\title{
Orthodontic Treatment of Ectopic Eruption of the Maxillary First Permanent Molar with Anterior Crossbite: A Case Report
}

ISSN: 2637-7764

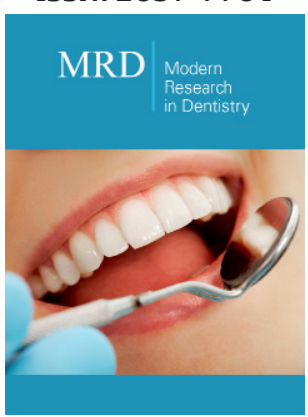

*Corresponding author: Youjian Peng, Department of Stomatology, Renmin Hospital of Wuhan University, No.238 Jiefang Road, Wuchang District, Wuhan, Hubei, China

Submission: 侮 May 25, 2020

Published: 此 July 02, 2020

Volume 5 - Issue 2

How to cite this article: Jiehua Zhang, Youjian Peng. Orthodontic Treatment of Ectopic Eruption of the Maxillary First Permanent Molar with Anterior Crossbite: A Case Report. Mod Res Dent. 5(2). MRD.000608. 2020.

DOI: 10.31031/MRD.2020.05.000608

Copyright@ Youjian Peng, This article is distributed under the terms of the Creative Commons Attribution 4.0 International License, which permits unrestricted use and redistribution provided that the original author and source are credited.

\section{Jiehua Zhang and Youjian Peng*}

Department of Stomatology, Renmin Hospital of Wuhan University, China

\begin{abstract}
s
The objective of this article is to describe the treatment of an 8-year-old boy with anterior crossbite and premature loss of the second primary molar due to the ectopic eruption of the maxillary first permanent molar. A modified Nance appliance was used to distalize the maxillary first permanent molar. And the crossbite of the anterior region was corrected by two-by-four $(2 \times 4)$ appliance. Satisfactory function was achieved for this patient, which greatly simplified the subsequent treatment in the permanent teeth.
\end{abstract}

Keywords: Ectopic Eruption; Crossbite; Modified Nance appliance

\section{Introduction}

The prevalence of ectopic maxillary first permanent molars in children has been reported as $3 \%-4 \%$ [1-3]. The etiology of ectopic eruption is related to genetic and environmental factors. The latter ones include small arches or a short maxillary length, significantly larger maxillary first permanent molars and maxillary second primary molars, a more mesial eruptive path of the permanent molar, and abnormal angulation of eruption of the maxillary first permanent molars. The ectopic eruption of a maxillary first permanent molar is frequently ignored and extremely challenging in dental practice. However, as the key to occlusion, the first permanent molars play a vital role in balanced occlusion. Failure to treat ectopic eruption could result in a local malocclusion. So early diagnosis and treatment can prevent a more complicated malocclusion.

\section{Case Presentation}

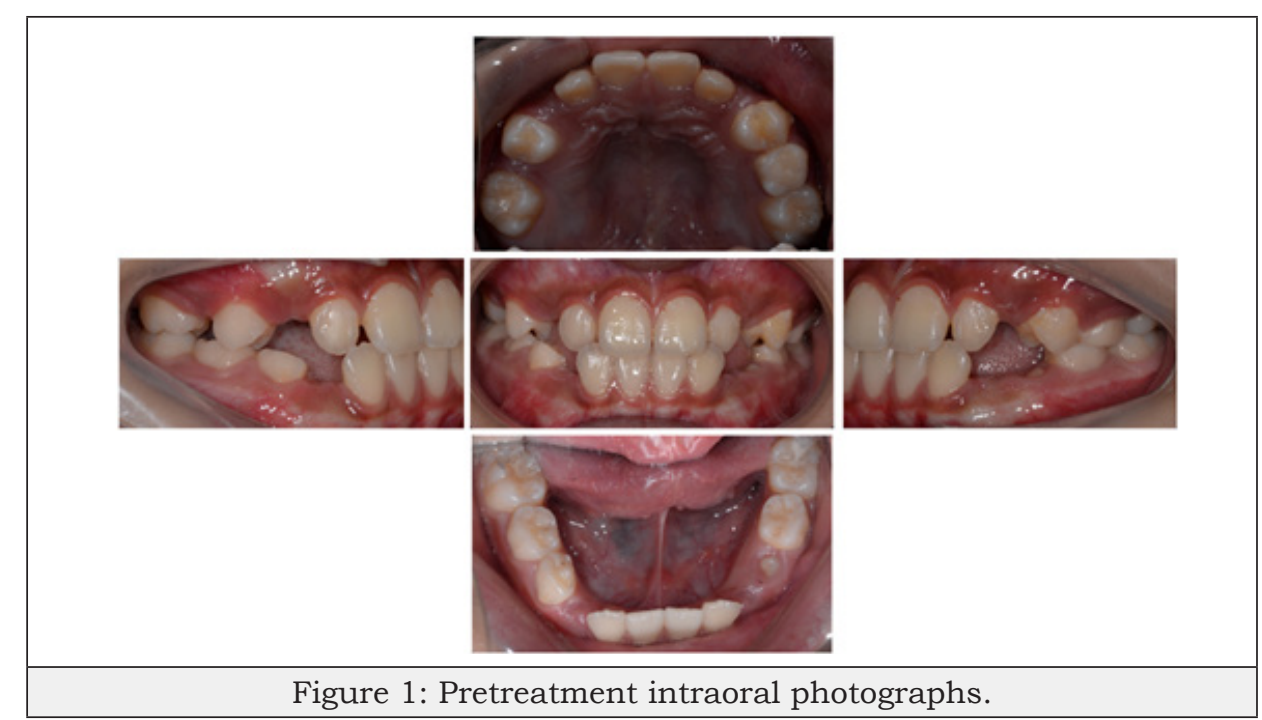


An 8-year-old boy sought orthodontic treatment at the office of our hospital in Wuhan, China. His chief complaint was to correct his anterior crossbite. He had a symmetrical face with a slightly concave profile. His facial midline was coincident with the dental midline. He was in a period of mixed dentition. The first maxillary molars presented a Class II molar relationship on both sides, with a crossbite of lateral incisors. He had a space of $2 \mathrm{~mm}$ between the right permanent maxillary first molar and premolar resulted from the early loss of the second primary premolar (Figure 1\&2A). The panoramic radiograph that was taken at the age of 5 years showed that atypical resorption of the second primary molar was caused by the mesial ectopic eruption of his right permanent maxillary first molar (Figure 2B).
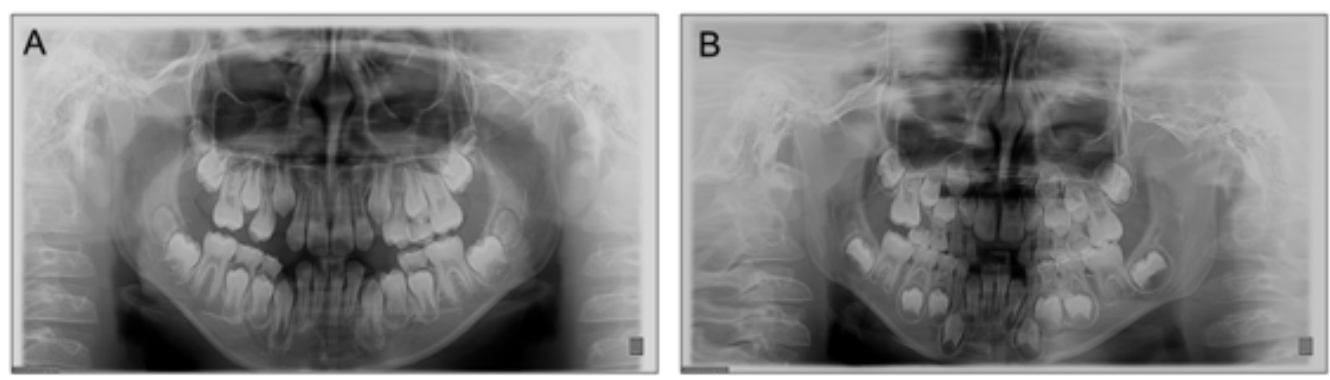

Figure 2:

A. Pretreatment panoramic radiograph at the age of 8 ;

B. Pretreatment panoramic radiograph at the age of 5 .
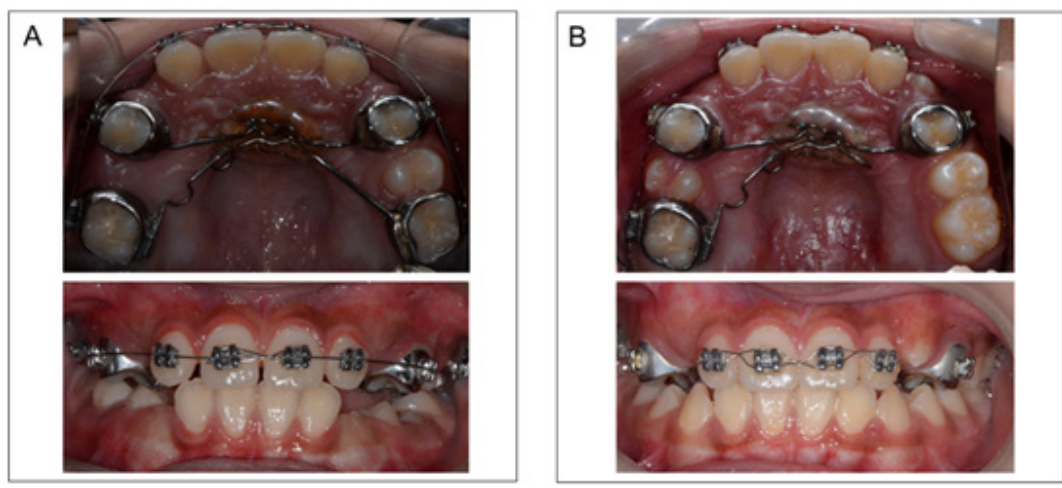

Figure 3: Treatment progress:

A. 2 months after the start of orthodontic treatment;

B. 5 months after the start of orthodontic treatment.
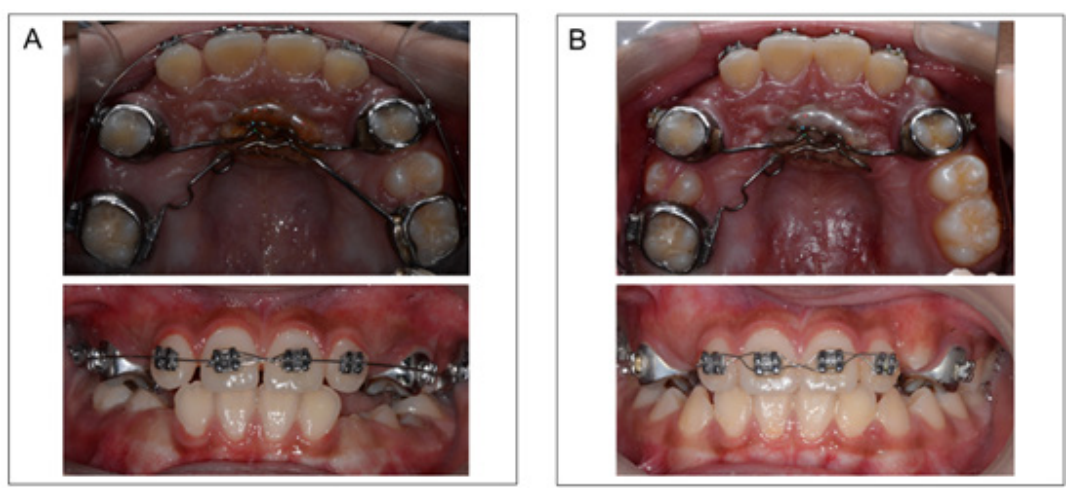

Figure 4: Posttreatment intraoral photographs.

0.012NiTi (NIC, Suhang, China) were placed and bonded on maxillary arch for alignment and crossbite correction in the anterior region. To reopen the space for the maxillary right second premolar, a modified Nance appliance was placed on the maxillary first permanent molars and the first premolars (Figure 3A). The crossbite was corrected after two months of treatment. At the end of the third month, $7 \mathrm{~mm}$ space was opened for the second premolar. The maxillary right second premolar erupted after a 5-month treatment (Figure 3B). The results maintained for 3 months and the active treatment ended. The posttreatment records 
showed that the treatment objectives were achieved (Figure 4). The facial photographs showed acceptable overbite and overjet were achieved. A Class I molar relationship was established.

\section{Discussion}

Abnormal mesial eruption of a maxillary first permanent molar may result in early loss of the second primary molar and incidence of the impaction in the second premolar. Except for allowing the selfcorrect and erupt into occlusion [3,4], possible treatment options include extraction of the second primary molar, a sectional fixed appliance, orthodontic separators (elastomeric, brass wire and pre-fabricated clip separators), or custom-made appliances $[5,6]$. In this case, a modified Nance appliance was used to regain lost space, upright the maxillary first permanent molar, and preserve arch length. Successful early intervention in the mixed dentition ensures proper full eruption of the permanent second premolar, which simplifies or even avoids comprehensive treatment of the malocclusion.

\section{References}

1. Pulver F (1968) The etiology and prevalence of ectopic eruption of the maxillary first permanent molar. Asdc J Dent Child 35(2): 138-146.

2. Bjerklin K, Kurol Jr, Paulin G (1993) Ectopic eruption of the maxillary first permanent molars in children with cleft lip and/or palate. Eur J Orthod 15(6): 535-540.

3. Barberialeache E, Suarezclúa MC, Saavedraontiveros D (2005) Ectopic eruption of the maxillary first permanent molar: characteristics and occurrence in growing children. Angle Orthod 75(4): 610-615.

4. Yuen S, Chan J, Tay F (1985) Ectopic eruption of the maxillary permanent first molar: the effect of increased mesial angulation on arch length. J Am Dent Assoc 111(3): 447-451.

5. Seehra J, Winchester L, Dibiase AT, Cobourne MT (2011) Orthodontic management of ectopic maxillary first permanent molars: a case report. Aust Orthod J 27(1): 57-62.

6. Kurol Jr, Bjerklin K (1985) Treatment of children with ectopic eruption of the maxillary first permanent molar by cervical traction. Am J Orthod 86(6): 483-492. 